\title{
Y nos siguen gustando los Krimis...
}

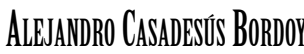 \\ Universidad de las Islas Baleares
}

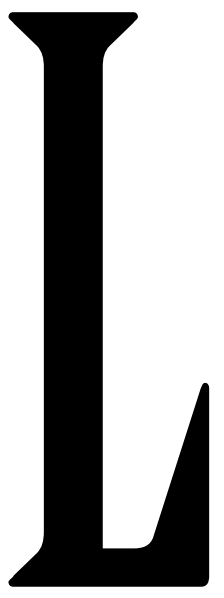

La popularidad de la novela policíaca, entendiendo este término como general para definir todas sus variantes y manifestaciones, es hoy en día un hecho en toda Europa y en Alemania, país en el que los Krimis, ya sean libros o series de televisión, han gozado desde los años 70 de una gran popularidad que aún se mantiene. El género policiaco disfruta actualmente de una envidiable salud que se demuestra en la gran cantidad de autores y libros que se pueden encontrar en las librerías, las audiencias que cosechan las series de televisión dedicadas a la investigación criminal y el prestigio mundial que han adquirido figuras como el italiano Camilleri o el sueco Mankell. Sin embargo, la popularidad del género no es un fenómeno nuevo puesto que las novelas del infalible Holmes, las andanzas de Marlowe, la meticulosidad de Poirot o la profunda sicología de Maigret han sido disfrutadas por diversas generaciones y son obras clásicas que han sentado las reglas que, con ciertas variaciones, siguen siendo vigentes.

La pregunta de por qué los Krimis gozan de tanta popularidad ha ocupado a algunos investigadores, críticos literarios y escritores que han intentado responder aportando diversas opiniones e hipótesis de difícil comprobación. La respuesta requeriría un trabajo de campo que abarcara a tantos lectores del género como fuera posible y les pidiera su opinión meditada y razonada. La imposibilidad de obtener estos datos con la máxima fiabilidad no se le escapa a los estudiosos del género. Hühn (1977: 296) admite que la última palabra la tiene el lector:

«Dieser sozialpsychologische Hintergrund bedarf jedoch ebenso [...] noch einer breiter angelegten empirischen Überprüfung, ehe man auch nur eini- germaßen gesicherte Aussagen über die Gründe für die Popularität der Detektivliteratur machen kann. Derartige empirischeForschungen dürften sich allerdings u.a. deswegen als sehr kompliziert erweisen, weil die von den meisten Kritikern postulierten unbewußten Motive einer experimentellen Analyse besonders schwer zugänglich sind».

Sin embargo, y pese a no disponer de esos datos, la estructura y la ideología del género permiten aventurar algunas hipótesis que, con toda probabilidad, coincidirían, al menos en su mayoría, con la opinión de los devotos de la novela policíaca.

La pregunta acerca de los motivos de tal interés de los lectores parece banal pero no lo es tanto si tenemos en cuenta que las estructuras y el planteamiento básico del género no han variado sustancialmente en sus aproximadamente 150 años de vida. Se comete un crimen, que inicia las pesquisas coordinadas por un investigador o investigadora que, gracias a sus características y métodos particulares consigue esclarecer el delito. Esta esencia se mantiene inalterable y el lector ya sabe que va a iniciar la lectura de una historia en la que se va a encontrar con ese planteamiento narrativo y, precisamente por este motivo, desea leer el libro. Umberto Eco (1975: 283) considera que en este punto reside el atractivo de la novela policíaca:

«El atractivo del libro, el sentido de reposo, de distensión psicológica que es capaz de comunicar, deriva del hecho de que [...] el lector encuentra una vez más, punto por punto, aquello que ya sabe, aquello que desea saber otra vez, y para lo cual ha pagado el precio de un libro». Por tanto, se puede argumentar en contra del género que consiste en la repetición de un esquema inamovible, que se va a repetir una y otra vez, y que no ofrece nada nuevo al lector. Desde esta perspectiva, la pregunta que nos planteamos cobra aún más interés puesto que el género ha demostrado poder pervivir sin grandes modificaciones y resistir el paso del tiempo, los cambios sociales y generacionales, las nuevas tecnologías, en definitiva, la evolución de la sociedad. ¿Qué encuentra el lector interesante en un género que no varía en exceso y mantiene sus estructuras básicas fijas?

Para intentar responder a esta pregunta dividimos el artículo en dos partes. En la primera se introducen de manera sintética, las variantes del género más importantes así como sus características principales desde el punto de vista ideológico y formal. En el segundo apartado se apuntan las posibles razones para justificar el éxito de la novela policíaca.

\section{Variar lo invariable. Algunas modalidades de la novela policíaca}

Peter Nusser (2003) divide en su estudio sobre los Krimis las manifestaciones del género en dos grandes grupos: las Detektivgeschichte y el Thriller entre los que incluye la variante más conocida, el hardboiled. La primera se identifica con la denominada «época dorada» que presenta un detective con unas capacidades casi sobrehumanas para la investigación, de cuya vida privada sabemos más bien poco y 
Ellatractivo del libro, el sentidido de reposo, de distensión psicológica que es capaz de comunicar,

que destaca por su infalibilidad. Es un personaje solitario, que siempre va acompañado de un ayudante que no puede nunca llegar a la altura intelectual y competencia del investigador y que entiende el crimen como un desafío a su inteligencia y habilidad. El crimen es un aliciente en su vida que le permite poner en marcha su maquinaria mental para interpretar todas las pistas e informaciones que consiga recopilar. Sus pesquisas siempre llegan a buen puerto y consigue dar con el criminal para ponerlo a disposición de la policía, una institución que no le merece mucho respeto puesto que considera que no están capacitados para resolver los delitos. Suele ser un detective amateur que no vive de la investigación sino que la lleva a cabo por placer.

La variedad hard-boiled presenta a un detective también solitario, íntegro y persistente, que se mueve en la gran ciudad, espacio anónimo por excelencia que favorece el crimen y la delincuencia, a la búsqueda de información y testigos, y que lucha contra la corrupción establecida. Portador de unos valores morales que no se estilan en la sociedad en la que le ha tocado vivir, el investigador privado malvive de su trabajo y, por una cantidad fija al día, se dedica a desenmascarar a criminales y personajes corruptos. Su presencia siempre genera incomodidad ya que es un personaje duro, violento, que no se asusta por ningún tipo de chantaje y que no se deja sobornar a pesar de su precariedad económica.

Desde el punto de vista ideológico, la primera variante ofrece una visión casi idílica de la sociedad, al menos desde la perspectiva actual, en la que la acción de un aficionado, consigue neutralizar el delito y con ello restablecer el orden quebrado y la sensación de amenaza para la sociedad burguesa, consolidada socialmente y temerosa de ataques a su integridad física y a sus propiedades. No se efectúa ningún tipo de reflexión moral sobre el crimen y sus circunstancias y se asocia la detención del criminal con la vuelta a la normalidad

\section{deriva del hecho de que [...] ell lector encuentra}

una vez más,puntopor punto, aquello que va sa-

be, aquello que desea saber otra vez, y para lo

cual ha pagado el precio de un libro.

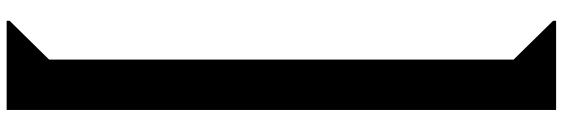

y a la vida segura y tranquila. El hard-boiled no presenta un esquema tan sencillo ni una división tan clara entre buenos y malos. El trabajo del detective, aunque culmine con éxito, no supone la tranquilidad ni el restablecimiento del orden establecido ya que la corrupción y la codicia, origen de muchos delitos, se encuentran profundamente enraizadas en la sociedad y no desaparecen por la intervención de un investigador privado.

La tercera variante y última que comentamos en este artículo ${ }^{1}$ se conoce como Polizeikrimi o, en inglés, police procedural. Los Polizeikrimis presentan el mundo del crimen y la investigación desde la perspectiva de la ley y la justicia que representa el cuerpo de policía. Suerbaum (1984: 160-168) y Waugh (1988: 120138) analizan esta variante en la que el protagonista es un policía, lo que no supone ninguna novedad en el género, y en la que el lector sigue las investigaciones a través de la perspectiva del cuerpo de policía teniendo acceso de este modo a sus métodos, organigrama y a los problemas que se derivan de este trabajo ya sean personales (del personaje principal) o profesionales (que afectan al personaje principal y a la investigación). Llama la atención que, siendo la policía un estamento cuyo origen se remonta a mediados del siglo XIX, su presencia en el género haya quedado relegada a un segundo plano hasta la irrupción de esta va- riante. Tanto en la época clásica como en el hard-boiled, la policía es un cuerpo inoperante y representado por funcionarios ineptos y poco preparados, es el caso de la época clásica de manera que se refuerza la inteligencia y capacidad del detective, o se trata de un cuerpo de policía desbordado por la criminalidad y corrupción cuando no es el mismo cuerpo un ejemplo de corrupción, como es el caso de los hard-boiled. Suerbaum (1984: 162) plantea esta problemática y concluye que una posible explicación sea el poco interés que despertaba la policía y sus métodos entre el público lector, especialmente en Inglaterra, cuna del género.

Suerbaum y Waugh resumen las características principales de esta variante atendiendo, en primer lugar, a la figura del investigador principal, que es el protagonista si bien debe compartir su protagonismo con otros compañeros así como jueces o forenses. El investigador es un funcionario y por tanto debe seguir unos protocolos y un código deontológico que le restan libertad de acción, una libertad de la que disfruta el detective aficionado o el tipo duro del hard-boiled. El personaje principal se aleja del superhombre de las variantes anteriores y su atractivo como personaje debe radicar en otros aspectos, como explica Waugh (1988: 133):

«Das Familienleben der Detektive etwa könnte untersucht werden - eine Gelegenheit, die in der klassischen und private-eye-Form des Kriminalromans niemals wahrgenommen wurde. Die Beziehungen der Männer untereinander können eine wichtige Rolle in einer Geschichte spielen. [...] Das Innenleben eines Kommissariats kann in der Tat den Hintergrund einer Serie liefern, damit die Leser die Polizisten, deren Charaktereigenschaften und deren Problemen so gut kennen lernen, daß sie sich auf das nächste Buch freuen, wiel sie es als eine Gelegenheit betrachten, alten Freunden wiederzubegegnen".

El hecho de que trabaje un grupo de policías coordinado por el personaje principal 
tiene como consecuencia inmediata que se investiguen dos o más casos a la vez -con la figura del investigador privado o amateur es imposible- y que se concentre en una región concreta en la que la comisaría y su equipo tienen su jurisdicción. La presión social sobre el investigador es muy grande, especialmente en casos que generan alarma social, aspecto que se suele resaltar de manera recurrente, para aumentar la sensación de realismo y de tensión en el relato. Esta variante ha aumentado con el paso del tiempo su popularidad, por un lado por la imagen positiva del cuerpo de policía y, por otro lado, porque ha encontrado un espacio natural en la televisión ${ }^{2}$.

\section{¿Y por qué gustan tanto?}

Si bien nadie puede atreverse a decir que existe un o unos motivos concretos, por la necesidad científica de contrastarlo con el mayor número posible de lectores, las teorías e hipótesis se basan en argumentos centrados en los aspectos formales, ideológicos y sociológicos. A continuación, se introducen los argumentos en los que la crítica e investigadores coinciden en señalar como posibles causas del éxito.

\section{Una novela de evasión:}

La crítica coincide en señalar que la novela policíaca supone una excelente válvula de escape, una evasión, por otra parte, inherente al propio acto de lectura y que se relaciona con la vida agitada y difícil que en la sociedad occidental se impone como modo de vida. Eckert (1971: 528) plantea la lectura de novela policíaca casi como una necesidad para escapar de la rutina:

«Die Gründe für die Beliebtheit des Kriminalromans liegen vor allem in unserer schnellebigen, technisierten, mechanisierten und rationalisierten Zeit, in welcher der gehetzte, von Sorgen bedrängte und mit Arbeit überlastete Mensch, vor allem der Großstädter, der in der Regel die natürlichen Bindungen zu den tiefen und innerlichen Werten des Lebens nur selten verspürt, nach einer Entspannung verlangt, die ihn den Alltag vergessen läßt.»

Röder (1971: 524), por su parte, entiende el género como una válvula de escape si bien no por la posible liberación que ejerce sobre la presión de la vida anónima y agobiante que ejerce la gran ciudad sino porque despierta, de manera segura, los instintos atávicos del ser humano: «Man neigt zu der Feststellung, daß der Kriminalroman wohl eine Art Ventildarstelle, durch das gewisse uralte menschlicheInstinkte und Triebkräfteharmlos und gefahrlos abreagiert werden könnten.» Esta cita resume la opinión de la mayoría de los críticos ${ }^{3}$ pero no justifica por sí misma cuáles son los motivos que inducen al lector a consumir este tipo de literatura o, formulado de otro modo, no explica qué elementos de la novela policíaca son los que hacen posible esa evasión que parece buscar el lector. Por este motivo, creemos conveniente analizar con más detalle qué aspectos hacen posible esa evasión.

\section{Género de fácil lectura}

El género policiaco no requiere un gran esfuerzo intelectual por parte del lector por lo que no está dirigido ni pensado para minorías intelectuales. Toca temas y sentimientos que todos pueden entender y con un estilo narrativo fresco, ágil y casi siempre repleto de acción. El lenguaje que se usa en estas obras es un factor decisivo. Cualquier lector con una formación básica puede leer y entender la novela en la que el registro coloquial, repleto de diálogos y expresiones de la calle, es frecuente. Este factor permite la lectura ágil de un texto elaborado sin complicaciones léxicas y $\sin$ grandes ejercicios de estilo o figuras retóricas elaboradas. Este factor atrae, con toda probabilidad, a la lectura. Marsch (1972: 23) matiza este argumento:

«Es wird nicht nur gelesen, weil er spannend ist, sondern weil er auch eine verstehbare, für jeden konsumierbare Gattung ist. Das sprachliche Material ist dem gerade aktuellen Lexikonbestand entnommen. Es ist nicht fremd, nicht extrem ästhetisch transformiert. Der Diktion des Alltags im Kriminalroman entspricht die Wirklichkeit der Sprache des Durchschnittsmenschen.»

$\mathrm{Si}$ a este factor le añadimos el hecho de que, como apunta Roas (2005: 54), «el género policiaco es fácilmente reducible a un determinado número de pautas y temas», podemos concluir que se trata de un género literario pensado para el consumo de la gran masa, sin exclusiones intelectuales, y con unas estructuras y clichés que, a fuerza de repetirse, facilitan aún más el proceso de leer y comprender el contenido. Se trata, en definitiva y co- mo afirma Heißenbüttel (1998: 120), de un género para todos:

«Überdies handelt es sich beim Kriminalroman um etwas, was so viele Kritiker der modernen Literatur vermissen: nämlich um legitimen Lesestoff für alle. Jeder kann sich in ihm wiederfinden. Den Kritikern allerdings scheint gerade dies nicht recht zu sein.»

De todos modos, conviene matizar este argumento atendiendo a la evolución que ha experimentado el género. Las novelas policíacas ofrecen en la actualidad aspectos muy sugerentes como la mayor complejidad de las tramas, una crítica social más profunda, o una construcción más elaborada de los personajes principales. Este refinamiento que ha alcanzado el género ha constituido, creemos, un factor de atracción importante para ganar nuevos lectores, más exigentes en sus gustos y que encuentran en las novelas actuales un placer que va más allá del descubrimiento del enigma o una acción violenta en el marco de la gran ciudad.

\section{El suspense y la intriga}

Las novelas policíacas, especialmente las novelas clásicas de detectives, plantean al lector un acertijo, un rompecabezas que éste quiere resolver ya que supone un desafío y un reto agradable para el lector. Este aspecto está directamente relacionado con la personalidad del lector, a quien le debe interesar este tipo de desafíos, y con la propia estructura del texto, que debe elaborarse de manera que mantenga esta tensión narrativa hasta el desenlace. De este modo lo entienden Roas (2005: 55) y Hühn (1977: 276), cuya cita incluimos a continuación:

«Diese Motivationsthese betont den Detektionsprozeß lediglich in seiner rein formalen, abstrakt-rationalen Dimension und verknüpft sie mit der Ebene der Neugier, des intellektuellen Spieltriebs beim Leser».

Se presenta al lector un misterio y un desafío que despiertan la natural curiosidad del ser humano: saber quién ha sido. Para Bertolt Brecht (1998: 35) el atractivo del género reside en ese planteamiento que destaca el trabajo intelectual:

"Aber der intellektuelle Genuß kommt zustande bei der Denkaufgabe, die der Kriminalroman dem Detektiv und dem Leser stellt.» 
El hecho de que el lector pueda competir en su proceso mental de deducción con el detective supone un aliciente añadido. Esta característica fue el motor principal de las obras clásicas de detectives puesto que éstas ofrecían tan sólo un enigma y el proceso deductivo hasta su resolución. Los cambios experimentados en el género han introducido nuevos aspectos si bien se sigue manteniendo el misterio como uno de los factores principales.

Crítica social, cercanía con el lector, identificación y realismo

Los tipos duros del hard-boiled son los protagonistas de una nueva variante que introduce la crítica social y la interpretación psicológica e ideológica del crimen. A partir de los años 30 la novela policíaca introduce la crítica social y el retrato psicológico, sociológico e ideológico $\mathrm{CO}-$ mo factores innovadores que se añaden a la simple resolución del enigma y que aumentan el interés del lector. La novela policíaca deja de ser un juego estético que no aporta más que un placer basado en resolver un misterio para ser un elemento de reflexión, de denuncia y de crítica social en el que el lector puede identificar los problemas de su ciudad o su país. Esta tendencia gana en fuerza a partir de los años 60 con la aparición de las obras de la pareja sueca Sjöwall y Wahlöö y su inspector de policía Martín Beck, que investiga en una Suecia no tan idílica ni apacible como parece ser. El éxito actual de esta variante demuestra que en una sociedad como la actual, en la que lo políticamente correcto maquilla y reprime la reflexión sobre ciertos problemas sociales, la novela policíaca ejerce como punto de equilibrio entre el realismo, la crítica y la denuncia de temas que afectan a todos y, por consiguiente, con los que todo lector se puede identificar. Montalbán (1999) opina al respecto:

«Gracias a la estrategia narrativa que supone la novela policíaca se puede abordar un discurso realista de una manera nueva. Estás describiendo la frontera que hay entre la política y el delito, entre lo ilegal y lo legal, la violación de un tabú como matar, los límites de las conductas, mientras estableces una complicidad con el lector.»

La sociedad se afronta desde una perspectiva diferente, que combina el misterio y

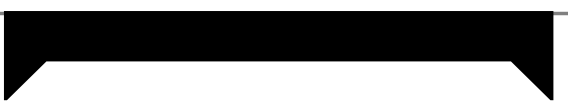

Aber da zeigt ihm (dem Leser) der Kriminalro-

mandiejenigenMilieus, vondenenerausgeschlos-

sen ist, und zu denen er mit Begehren und Angst

gleichzeitig eingestellt ist.

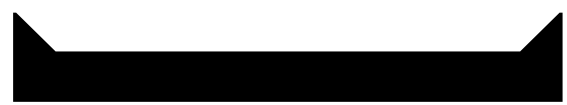

la crítica, ofreciendo una imagen de lo cotidiano, de la realidad que nos envuelve que permite esa complicidad mencionada por Montalbán.

Morboy amenaza, tranquilidad e intranquilidad La novela policíaca despierta el interés natural en el ser humano por los aspectos morbosos y truculentos de la vida. Es un instrumento ideal para entrar en una parte de la sociedad, en un mundo que, en la misma medida que atrae, atemoriza. Se enfrenta al lector con una realidad que, en condiciones normales, se encuentra muy alejada de su realidad si bien sabe de su existencia. El lector sabe que existe un mundo violento, con unos códigos morales y unas reglas no escritas que desafían el orden social establecido, la tranquilidad y la paz. Ese ambiente existe, no es una ficción literaria, se encuentra en cada ciudad y en cada sociedad y en muchas ocasiones se encuentra más cercano de lo que el lector pueda saber. Con esas premisas juega la novela policíaca que aproxima al lector a un mundo real pero desconocido para él y lo hace desde una perspectiva de ficción. Por tanto, desde una perspectiva segura, que permite ser testigo de actos violentos, delitos, tramas corruptas o sobornos, por poner algunos ejemplos, desde la butaca de casa, en el trabajo o en un medio de transporte. La novela policíaca introduce a su público en un mundo peligroso, atrayente y real, ofreciendo la debida distancia y seguridad que ofrece la ficción. En esa mezcla de seguridad e inseguridad, de miedo y tranquilidad se basa este argumento. El lector quiere ver, quiere ser testigo de lo que sucede, o puede suceder, en los ambientes más sórdidos pero sin ser, porque es consciente del peligro que entraña, más que un mero espectador que asiste al desarrollo de una historia. Marsch (1972: 40) y Chesterton (1971: 502) apuntan:

«Der Autor setzt einen Fall und gestaltet ihn so wahrscheinlich, daß der Leser den Eindruck hat, hier ereigne sich eine für das Leben nicht allzu häufige, aber doch mögliche Ausnahmesituation menschlichen Verhaltens. Was in Wirklichkeit nicht möglich ist, ist für die Kriminalliteratur geradezu typisch: der Leser darf Zeuge sein, ohne eingreifen zu müssen.»

«Aber da zeigt ihm (dem Leser) der Kriminalroman diejenigen Milieus, von denen er ausgeschlossen ist, und zu denen er mit Begehren und Angst gleichzeitig eingestellt ist.»

El esquema típico de la novela policíaca plantea un juego muy interesante entre la tranquilidad y el miedo que parece atraer al lector. La trama genera una inseguridad y una angustia, que se basa en la violencia, en la muerte y en la aparente imposibilidad de resolver el caso. El delincuente rompe el orden social establecido, lo desestabiliza y el detective o el investigador deben detenerle y esclarecer el caso para poder devolver la situación a la normalidad. Este aspecto ideológico es especialmente claro en las novelas clásicas de detectives, en las que el trabajo del detective, siempre exitoso, supone el restablecimiento absoluto del orden y la paz, lo que tranquiliza al lector después de haber sufrido la inquietud y el desasosiego. Richard Alewyn (1998: 71) considera esta mezcla de miedo y tranquilidad como una de las claves del éxito:

«Was ihm (dem Kriminalroman) noch heute Millionen zivilisierter Leser zuführt, ist das Bedürfnis nicht nach einer Bestätigung der trivialen Wirklichkeit, sondern nach ihrer Verfremdung -ein vielleicht perverser, vielleicht normalerHunger nach Geheimnis, ein bißchen Unsicherheit und ein bißchen Angst.» En el caso de las novelas hard-boiled, la sensación de intranquilidad no sólo se transmite por el crimen cometido sino también por la imagen de corrupción y de crítica social. El realismo, que permite una gran identificación del lector con los problemas y crímenes relatados, aumenta esa sensa- 
ción de inseguridad por la proximidad, ya sea física o emocional, del tema que se trata. Esta proximidad hace pensar al lector que lo que se narra sucede en la realidad $y$, tal vez, él mismo pueda ser una víctima en el futuro. Esa combinación entre inseguridad y seguridad se consigue gracias a la distancia de la ficción y al propio argumento que, al menos en una de las variantes, asegura que el orden se restablezca ${ }^{4}$. En definitiva, nos gusta leer y contemplar sin riesgo alguno aquello que en la vida real aborrecemos y condenamos por su carácter asocial y peligroso.

\section{Conclusiones}

La buena salud literaria que actualmente goza el género demuestra que los gustos de los lectores no han variado tanto a lo largo de su historia. Las diferentes variantes, de las que en este artículo resaltamos tan sólo algunas y de manera comprimi$\mathrm{da}$, juegan con una serie de factores y valores universales que, por ser inherentes al ser humano garantizan el interés del lector. Se trata, en definitiva, de una literatura de evasión, que aparta al lector de su mundo y su ambiente para colocarlo en otro mucho más sórdido y peligroso y, por consiguiente, interesante. Las novelas policíacas se leen de manera fluida y amena porque no exigen, en el plano intelectual demasiado del lector: tan sólo provocan su curiosidad, le plantean un delito y un desafío y le conducen por el proceso de investigación que varía según la manifestación concreta del género que tengamos entre manos. La evolución hacia una crítica social cada vez más acentuada así como una mayor solidez narrativa, son puntos destacables que atraen al lector, que ve reflejado su entorno desde una perspectiva diferente. De todos modos, la clave del éxito se encuentra en la combinación de todos los factores expuestos en el artículo y no sólo en uno de ellos. Roas (2005: 59) resume a la perfección esta idea:

«Pero, pese a todo, ése no es el único objetivo de nuestra lectura, puesto que si sólo buscáramos testimonios críticos que constatasen dicha corrupción, acabaríamos leyendo novelas sociales o ensayos sociológicos. Para que el cóctel de la novela negra tenga todo su sabor hay que añadirle la necesaria cantidad de misterio y crimen.»

En definitiva, la novela policíaca demues- tra la complejidad y las contradicciones del ser humano en toda su dimensión. Nadie quiere morir asesinado, ni ser víctima de un chantaje o una extorsión. Todos condenamos la violencia y el asesinato y soñamos con una sociedad en la que esto no existiera. Sin embargo, todos, o muchos, leemos novela policíaca con fruición deseando saber cómo ha muerto el personaje y quién ha tenido la sangre fría de ordenar-

\section{Bibliografía}

Alewyn, R. (1998), Anatomie des Detektivromans, en Vogt, J. (ed.) (1998), Der Kriminalroman. Poetik, Theorie, Geschichte. München, Wilhem Fink Verlag, 52-72.

Brecht, B. (1938/1940), Über die Popularität des Kriminalromans, en Vogt, J. (ed.)(1998), 33-37.

Chesterton, G.K., (1971), Verteidung von Detektivgeschichten, en Vogt, J. (ed.) (1971), 95-98.

Delgado Gómes, A. (1999), Reivindicación de la novela negra. en CLIJ: Cuadernos de literatura infantil y juvenil, 117, 58-62.

Eco, U. (1975), Apocalípticos e integrados ante la cultura de masas. Barcelona, Lumen. Eckert, O. (1971), Der Kriminalroman als Gattung, en Vogt, J. (ed.) (1971), 528-532.

Heißenbüttel, H. (1998), Spiegelregeln des Kriminalromans. en Vogt, J. (ed.) (1998), 111-120.

Hühn, P. (1977), Zu den Gründen für die Popularität des Detektivromans. Eine Untersuchung von Thesen über die Motive seiner Rezeption, en Arcadia 12, 273-296.

Manzano, E. (18/04/1999), Charla entre Camilleri y Vázquez Montalbán, La Vanguardia Magazine

Nusser, P. (2003), Der Kriminalroman. Stuttgart, J.B. Metzler,.

Roas, D. (2005), ¿Porqué leemos (todavía) novelas policíacas?, en Quimera: Revista de literatura, 259-260, 54-59.

Röder, R. (1971), Zur Frage des Kriminalromans, en Vogt, J. (ed.) (1971), 523-528.

Suerbaum, U. (1984), Krimi. Eine Analyse der Gattung. Stuttgart, Reclam.

Waugh, H. (1988), Das Police Procedural. Der Polizeiroman. en: Ball, J., (1988), Morde, Meister und Mysterien. Die Geschichte des Kriminalromans. Berlín, Ullstein, 120138.

Wilson, E. (1971), Warum werden Detektivromanegelesen?, en Zmegac, V. (ed.) (1971), lo y ejecutarlo. Queremos saber cómo funciona ese mundo, esa parte de la sociedad que evitamos y no queremos conocer de primera mano. Queremos saber cómo piensa y actúa el criminal aunque nos atemorice y no queramos vivir con él cerca. Queremos que se critique lo que no funciona, aunque, quizá, seamos en parte responsables. Al fin y al cabo tan sólo somos seres humanos y, por tanto, somos imperfectos.

Der wohltemperierte Mord. Zur Theorie und Geschichte des Detektivromans. Frankfurt am Main, Athenäum.

\section{Notas}

1. Por supuesto existen más variantes que no se tratan en este artículo en el que nos centramos en tres de las más populares. Mencionamos a modo de reseña otras variantes destacadas como los

Psychokrimis, los Krimis con protagonistas y ambientes homosexuales o los Frauenkrimis, escritos y pensados para un público femenino.

2. Tatort es el mejor ejemplo en Alemania. Con casi 36 años en antena (ARD), la serie sigue emitiéndose con un gran éxito de audiencia. El primer episodio se emitió el 29 de noviembre de 1970 -titulado Taxi nach Leipzig- y a partir de ese momento han aparecido más de 70 comisarios y grupos de investigación diferentes. Una posible explicación para este rotundo éxito es la diversificación regional de los crímenes ya que cada región tiene su equipo especializado. En la actualidad son 15 grupos de investigación, uno de ellos en Viena, el resto repartidos por la geografía alemana en ciudades como Berlin, Leipzig, München o Stuttgart entre otras.

3. Ver Roas (2005: 54), Schmidt (1989: 63), Nusser (2003: 151-168). Todos coinciden en señalar este factor como uno de los principales

4. Hühn (1977: 278-281) analiza con mayor profundidad, a partir de diferentes interpretaciones de los críticos, lo que se entiende por orden establecido. Hühn interpreta que, al menos, existen tres maneras de entender el concepto: la existencialista, la religiosa y la filosófica. Cada una de ellas sostiene una idea diferente de orden. 